\title{
Interferon alpha treatment and endocrine disease
}

\author{
Wing Bun Chan MRCP Chun Chung Chow FRCP Clive Stewart Cockram MD FRCP
}

J R Soc Med 2003:96:481-485

The interferons are a group of proteins with antiviral activity, growth regulatory properties, and a wide variety of immunomodulatory activities. There is evidence that, when interferon $\alpha$ is used therapeutically in chronic hepatitis $\mathrm{B}$ and $\mathrm{C}$ and in certain malignancies, ${ }^{1-5}$ it can precipitate or exacerbate autoimmune endocrine diseases, especially of the thyroid gland. ${ }^{6}$ In this review we examine the published information on such unwanted effects.

\section{THYROID GLAND}

The thyroid gland is the most extensively studied in relation to the effect of interferon $\alpha$ : more than forty reports document changes in thyroid function and autoimmune markers during treatment of hepatitis C. In the largest series, 11241 consecutive patients with hepatitis $\mathrm{C}$ were treated with interferon $\alpha$, of whom $71(0.6 \%)$ developed symptomatic thyroid disorders. ${ }^{7}$ This incidence, however, is likely to be an underestimate: there was no regular surveillance of thyroid function, so symptoms related to thyroid disorders could easily have been missed or misinterpreted. Series in which thyroid function was checked regularly have shown thyroid dysfunction developing in $4-14 \%$ of patients during interferon $\alpha$ therapy. ${ }^{8-10}$ If development of circulating thyroid antibody is included, the percentage is much higher. ${ }^{11-13}$ Table 1 summarizes results from the studies with sizeable numbers. A noteworthy feature is that the more frequently thyroid function was checked the higher the reported rate of thyroid dysfunction.

In hepatitis $\mathrm{C}$, interpretation of the data is complicated by the fact that this disease is itself associated with autoimmune disorders. ${ }^{14}$ For example, up to $20 \%$ of chronic hepatitis $\mathrm{C}$ patients have circulating thyroid antibody before treatment with interferon $\alpha .{ }^{15-17}$ The question whether interferon $\alpha$ precipitates or worsens thyroid dysfunction would best be settled by a randomized placebo-controlled trial, in which the treated and untreated groups would be comparable. No such trial has yet been reported, so we have to assess evidence from less reliable

Department of Medicine and Therapeutics, Prince of Wales Hospital, The Chinese University of Hong Kong, Shatin, NT HKSAR.

Correspondence to: Dr WB Chan

E-mail: wbchan@cuhk.edu.hk comparisons. In one recent study the incidence of thyroid antibody development in patients treated with interferon $\alpha$ was $21 \%$ compared with $10 \%$ in patients not so treated. ${ }^{11}$ The difference was not statistically significant and the authors judged the thyroid autoimmunity more likely to be due to the virus infection than to the treatment. However, there were only 65 patients in each group and the study lacked the statistical power for a confident negative conclusion. Another study, with similar design, showed a larger difference, with 9/58 (16\%) initially seronegative patients developing thyroid autoimmunity when on interferon compared with 1/28 (3\%) of those declining the treatment. Although the data are inconclusive, we think it likely that interferon $\alpha$ can exacerbate pre-existing thyroid immunity.

The patients most at risk of developing either biochemical or clinical thyroid autoimmune disease during interferon $\alpha$ treatment are women and people with preexisting thyroid peroxidase antibody. ${ }^{18-21}$ Other possible risk factors are advanced age and oriental origin. ${ }^{10,18,19}$ Of individuals with pre-existing thyroid peroxidase antibody, half or more have been reported to develop thyroid dysfunction during interferon $\alpha$ treatment. ${ }^{20,21}$ The disorders include hypothyroidism (the most common ${ }^{13,22}$ ), Graves' disease with hyperthyroidism and thyroiditis with a two-phase presentation. The pattern of thyroid dysfunction seems to differ between patients with pre-existing antibody and those without: patients with pre-existing thyroid peroxidase antibody tend to develop either an exacerbation of Graves' disease or Hashimoto's thyroiditis during interferon treatment, while those without pre-existing antibody tend to develop thyroiditis. ${ }^{18,23,24}$ This is illustrated by the work of Roti et al. ${ }^{25}$ who found that 4 out of 32 patients treated with interferon developed thyrotoxicosis during treatment. Interestingly, 3 of the 4 showed a decreased uptake of radioactive iodine, suggesting a destructive process, and the thyrotoxicosis subsided with steroid therapy. Furthermore, all 4 were negative for thyroid peroxidase antibody. ${ }^{25}$ We think it likely that, in certain series, some of the cases reported as Graves' disease are in fact thyroiditis - caught in the initial thyrotoxic phase and thus misdiagnosed.

One reason for thinking that interferon $\alpha$ is a direct cause of thyroid dysfunction is that in some instances the dysfunction ceases when treatment stops. However, this is 


\begin{tabular}{|c|c|c|c|c|}
\hline Reference & $\begin{array}{l}\text { No. receiving } \\
\text { interferon } \\
\text { alpha }\end{array}$ & $\begin{array}{l}\text { Newly developed } \\
\text { thyroid } \\
\text { dysfunction }\end{array}$ & $\begin{array}{l}\text { Newly developed } \\
\text { thyroid } \\
\text { antibody }\end{array}$ & Remarks \\
\hline Fattovich (Ref. 7) & 11241 & $0.6 \%$ & NR & Relied on clinical reporting only \\
\hline Marazuela. (Ref. 10) & 144 & $3.2 \%$ & $4.8 \%$ & Monitored at 12 and 24 weeks \\
\hline Okanoue (Ref. 9) & 677 & $6.4 \%$ & NR & Monitored at the end of therapy \\
\hline Murakami (Ref. 8) & 439 & $3.9 \%$ & NR & \\
\hline Carella (Ref. 26) & 114 & $7.0 \%$ & $31 \%$ & 6.2 year prospective data after stoppng interferon $\alpha$ \\
\hline Carella (Ref. 27) & 147 & $9.5 \%$ & $23 \%$ & Monitored before therapy, and at 6 months and 1 year \\
\hline Carella (Ref. 12) & 75 & $5.3 \%$ & $45.3 \%$ & Monitored before therapy and at 6 months and 1 year \\
\hline Kryczka (Ref. 13) & 120 & $33.3 \%$ & NR & Monitored at 4 week intervals \\
\hline Fernandez-Soto (Ref. 15) & 134 & $12 \%$ & $20 \%$ & Monitored at baseline and 6 months \\
\hline Dalgard (Ref. 22) & 254 & $11.8 \%$ & $\begin{array}{l}6.5 \% \text { (only TPO } \\
\text { included) }\end{array}$ & Monitored at baseline and 3,6 and 12 months \\
\hline Watanabe (Ref. 20) & 109 & $8.3 \%$ & NR & Monitored every other month \\
\hline Hsieh (Ref. 19) & 150 & $18.7 \%$ & NR & Monitored every 3 months \\
\hline
\end{tabular}

$\mathrm{NR}=$ not reported TPO $=$ peroxidase antibodies

not universal: some patients continue to need treatment such as thyroid hormone replacement for a long time after stopping interferon. Antibody production follows a similar pattern. In some patients antibodies decline or disappear when interferon is stopped, in others they persist. ${ }^{10,15,18}$ Carella et al. ${ }^{26}$ followed 114 patients after a course of interferon for hepatitis C. At the end of twelve months of treatment, $36(32 \%)$ had thyroid antibody. At a median follow-up of 6.2 years, about one-third still had antibody, one-third had lost their antibody while the remaining third showed a relapsing/remitting pattern. Of the 12 patients in this series who developed subclinical hypothyroidism, all were in the group with thyroid antibodies. The findings point to the need for continued surveillance of thyroid function when interferon $\alpha$ treatment is stopped. The same group looked at patients who received ribavirin in addition to interferon $\alpha$, but the incidence of thyroid dysfunction was similar. ${ }^{27}$ Apart from true thyroid dysfunction, interferon $\alpha$ has also been reported to induce antithyroxine antibody, which can give rise to a spuriously high free T4 measurement unless special assay procedures are followed. This further complicates the picture. $^{28}$

Interferon $\alpha$ has also been used in the treatment of hepatitis B and hepatitis D. In these contexts, thyroid dysfunction seems less frequent than in hepatitis $\mathrm{C}$, though the matter has been less well studied. In hepatitis $\mathrm{B}$, the prevalence of antibodies before interferon treatment is lower only $2-4 \% .^{15,17}$ Because of the lower incidence, monitoring of thyroid function is probably not indicated in these patients after interferon $\alpha$ treatment, in the absence of symptoms.

Interferon has also been used in the treatment of malignant disease, including haematological malignancy, carcinoid tumour, metastatic melanoma and breast cancer. ${ }^{1,3,5}$ In patients with carcinoid tumour or breast cancer the incidence of thyroid dysfunction during interferon treatment can be very high-usually 20-30\% and sometimes $50 \% .{ }^{29-30}$ Both Hashimoto's thyroiditis and Graves' disease have been reported. However, most series are rather small and long-term data are lacking. In patients with haematological malignancy treated with interferon, the incidence of thyroid dysfunction during interferon treatment is much lower. ${ }^{31,32}$ The reason for such differences is obscure.

Possibly different mechanisms are at work in different types of thyroid dysfunction. In healthy individuals injected with interferon $\alpha$, thyroid stimulating hormone (TSH) and tri-iodothyronine (T3) decrease while reverse T3 increases. This biochemical picture is similar to euthyroid sick syndrome and may be mediated through interleukin $6 .{ }^{33}$ Such acute effects are unlikely to account for the thyroid dysfunction described in patients receiving longer-term treatment. Other effects of interferon $\alpha$ are to increase expression of major histocompatibility complex class I antigen but suppress the expression of histocompatibility complex class II antigen. ${ }^{34}$ However, autoimmune thyroid diseases are characterized by increased rather than decreased expression of histocom- 
patibility complex class II antigen. ${ }^{35}$ Furthermore, work in animals suggests that the increased production of thyroid antibody and expression of histocompatibility complex class I and II antigen are dissociated. ${ }^{36,37}$ The role of such changes in the development of autoimmune thyroid diseases during interferon $\alpha$ therapy remains speculative. Interferon $\alpha$ is known to alter the balance between Th1 and Th2 cells. Th1 cells predominate in Hashimoto's thyroiditis while Th2 cells have an important role in Graves' disease. ${ }^{38,39}$ We hypothesize that interferon $\alpha$ causes autoimmune thyroid disease by changing the Th1/Th2 balance. It is also noteworthy that another cytokine, interferon $\beta$, has been incriminated in induction of thyroid dysfunction. ${ }^{40}$

\section{DIABETES MELLITUS}

Endocrine disorders of other kinds have been less thoroughly studied than thyroid dysfunction in relation to interferon therapy. There are several reported cases of type 1 diabetes developing in association with interferon treatment, but most of the patients had GAD antibodies before the start of treatment. ${ }^{41,42}$ In one series of 70 patients with hepatitis $\mathrm{C}$ receiving interferon, only 1 developed type 1 diabetes (five months after the beginning of treatment) and that patient was anti-GAD positive before treatment. The causal role of interferon is therefore doubtful. ${ }^{43}$

\section{ADRENAL DYSFUNCTION}

Anti-21-hydroxylase antibody has been reported to appear in $4.8 \%$ of hepatitis $\mathrm{C}$ patients receiving interferon therapy. ${ }^{44}$ However, to date there has been no report of adrenal failure associated with this phenomenon. There are two reports of pre-existing Addison's disease showing increased steroid dependence during interferon therapy. ${ }^{45,46}$

\section{PITUITARY DYSFUNCTION}

Interferon $\alpha$ can activate the hypothalamic-pituitary axis in acute circumstances. ${ }^{47}$ There is one reported case of reversible hypopituitarism in association with interferon therapy ${ }^{48}$ and our group has seen a patient with irreversible hypopituitarism after one year of interferon therapy (unpublished).

\section{OTHER AUTOIMMUNE DISORDERS}

From the published work it is clear that thyroid dysfunction is the most common endocrine disorder to develop during interferon $\alpha$ therapy. The likely reason is that the thyroid is the most common site of autoimmune endocrine disease in the general population and that interferon $\alpha$ treatment promotes autoimmune reactions especially in those who are immunologically predisposed (antibody positive before treatment). Probably the risk of other autoimmune disorders is likewise increased but less obvious because these conditions are rarer or more difficult to detect. This notion is supported by the development of other autoimmune diseases such as systemic lupus erythematosus and Sjögren's syndrome during interferon $\alpha$ treatment. ${ }^{49}$

\section{RECOMMENDATIONS}

Since the incidence of thyroid dysfunction is quite high in patients receiving interferon $\alpha$ for hepatitis $\mathrm{C}$ and certain malignancies (including malignant carcinoid and breast cancer), we recommend that thyroid function and thyroid antibody be checked before initiation of treatment for these conditions and monitored during treatment. By contrast, in patients receiving the agent for hepatitis B or haematological malignancy, monitoring of thyroid function may not be worthwhile in the absence of symptoms. If thyrotoxicosis develops during interferon treatment, physicians should also be aware of the possibility of destructive thyroiditis as distinct from Graves' disease with hyperthyroidism. This is particularly true for patients without pre-existing thyroid antibody. Thyroid dysfunction may resolve if interferon is stopped. However, the development of thyroid dysfunction does not necessarily contraindicate further interferon $\alpha$ treatment. Of those patients who are antibody positive at the end of interferon treatment, a proportion will later develop thyroid dysfunction; therefore continued monitoring of thyroid function is needed in this group. Interferon $\alpha$ induced type 1 diabetes, adrenal insufficiency and hypopituitarism seem rare although antibodies directed against the corresponding organ have been reported. Regular monitoring for these disorders is not indicated.

\section{REFERENCES}

1 Kloke O, Opalka B, Niederle N. Interferon alfa as primary treatment of chronic myeloid leukemia: long-term follow-up of 71 patients observed in a single center. Leukemia 2000;14:389-92

2 Lindsay KL. Introduction to therapy of hepatitis C. Hepatology 2002;36(5 Suppl 1):S114-20

3 Oberg K. The action of interferon alpha on human carcinoid tumours. Semin Cancer Biol 1992;3:35-41

4 Wong DK, Cheung AM, O'Rourke K, Naylor CD, Detsky AS, Heathcote J. Effect of alpha-interferon treatment in patients with hepatitis B e antigen-positive chronic hepatitis B. A meta-analysis. Ann Intern Med 1993;119:312-23

5 Agarwala SS, Kirkwood JM. Update on adjuvant interferon therapy for high-risk melanoma. Oncology (Huntingt) 2002;16:1177-87; discussion 1190-2, 1197 
6 Chedin P, Chanson P, Duranteau L, Guillausseau PJ, Lubetzki J. Dysthyroidism in patients treated with interferon alpha. Presse Med 1994;23:1659-63

7 Fattovich G, Giustina G, Favarato S, Ruol A. A survey of adverse events in 11,241 patients with chronic viral hepatitis treated with alfa interferon. J Hepatol 1996;24:38-47

8 Murakami M, Kakizaki S, Takayama H, Takagi H, Mori M. Autoimmune thyroid disease induced by interferon therapy. Nippon Rinsho 1999; 57:1779-83

9 Okanoue T, Sakamoto S, Itoh Y, et al. Side effects of high-dose interferon therapy for chronic hepatitis C. J Hepatol 1996;25:283-91

10 Marazuela M, Garcia-Buey L, Gonzalez-Fernandez B, et al. Thyroid autoimmune disorders in patients with chronic hepatitis $\mathrm{C}$ before and during interferon-alpha therapy. Clin Endocrinol (Oxf) 1996;44:635-42

11 Rocco A, Gargano S, Provenzano A, et al. Incidence of autoimmune thyroiditis in interferon-alpha treated and untreated patients with chronic hepatitis C virus infection. Neuroendocrinol Lett 2001;22:39-44

12 Carella C, Amato G, Biondi B, et al. Longitudinal study of antibodies against thyroid in patients undergoing interferon-alpha therapy for HCV chronic hepatitis. Horm Res 1995;44:110-14

13 Kryczka W, Brojer E, Kowalska A, Zarebska-Michaluk D. Thyroid gland dysfunctions during antiviral therapy of chronic hepatitis C. Med Sci Monit 2001;7 (Suppl 1):221-5

14 Cacoub P, Renou C, Rosenthal E, et al. Extrahepatic manifestations associated with hepatitis $\mathrm{C}$ virus infection. A prospective multicenter study of 321 patients. The GERMIVIC. Groupe d'Etude et de Recherche en Médecine Interne et Maladies Infectieuses sur le Virus de l'Hépatite C. Medicine (Baltimore) 2000;79:47-56

15 Fernandez-Soto L, Gonzalez A, Escobar-Jimenez F, et al. Increased risk of autoimmune thyroid disease in hepatitis $\mathrm{C}$ vs hepatitis $\mathrm{B}$ before, during, and after discontinuing interferon therapy. Arch Intern Med 1998; 158:1445-8

16 Huang MJ, Tsai SL, Huang BY, Sheen IS, Yeh CT, Liaw YF. Prevalence and significance of thyroid autoantibodies in patients with chronic hepatitis $\mathrm{C}$ virus infection: a prospective controlled study. Clin Endocrinol (Oxf) 1999;50:503-9

17 Preziati D, La Rosa L, Covini G, et al. Autoimmunity and thyroid function in patients with chronic active hepatitis treated with recombinant interferon alpha-2a. Eur $J$ Endocrinol 1995; 132:587-93

18 Custro N, Montalto G, Scafidi V, et al. Prospective study on thyroid autoimmunity and dysfunction related to chronic hepatitis $\mathrm{C}$ and interferon therapy. J Endocrinol Invest 1997;20:374-80

19 Hsieh MC, Yu ML, Chuang WL, et al. Virologic factors related to interferon-alpha-induced thyroid dysfunction in patients with chronic hepatitis C. Eur J Endocrinol 2000;142:431-7

20 Watanabe U, Hashimoto E, Hisamitsu T, Obata H, Hayashi N. The risk factors for development of thyroid disease during interferonalpha therapy for chronic hepatitis C. Am J Gastroenterol 1994;89:399-403

21 Murakami T, Masumoto T, Michitaka K, et al. Prediction of interferon-alpha-induced thyroid dysfunction in patients with chronic hepatitis C. J Gastroenterol Hepatol 1995;10:528-31

22 Dalgard O, Bjoro K, Hellum K, et al. Thyroid dysfunction during treatment of chronic hepatitis $\mathrm{C}$ with interferon alpha: no association with either interferon dosage or efficacy of therapy. J Intern Med 2002;251:400-6

23 Amenomori M, Mori T, Fukuda $\mathrm{Y}$, et al. Incidence and characteristics of thyroid dysfunction following interferon therapy in patients with chronic hepatitis C. Intern Med 1998;37:246-52

24 Mazziotti G, Sorvillo F, Stornaiuolo G, et al. Temporal relationship between the appearance of thyroid autoantibodies and development of destructive thyroiditis in patients undergoing treatment with two different type-1 interferons for HCV-related chronic hepatitis: a prospective study. $J$ Endocrinol Invest 2002;25:624-30

25 Roti E, Minelli R, Giuberti T, et al. Multiple changes in thyroid function in patients with chronic active HCV hepatitis treated with recombinant interferon-alpha. Am J Med 1996;101:482-7

26 Carella C, Mazziotti G, Morisco F, et al. Long-term outcome of interferon-alpha-induced thyroid autoimmunity and prognostic influence of thyroid autoantibody pattern at the end of treatment. $J$ Clin Endocrinol Metab 2001;86:1925-9

27 Carella C, Mazziotti G, Morisco F, et al. The addition of ribavirin to interferon-alpha therapy in patients with hepatitis $\mathrm{C}$ virus-related chronic hepatitis does not modify the thyroid autoantibody pattern but increases the risk of developing hypothyroidism. Eur $J$ Endocrinol 2002;146:743-9

28 Papo T, Oksenhendler E, Izembart M, Leger A, Clauvel JP. Antithyroid hormone antibodies induced by interferon-alpha. $J$ Clin Endocrinol Metab 1992;75:1484-6

29 Fentiman IS, Balkwill FR, Thomas BS, Russell MJ, Todd I, Bottazzo GF. An autoimmune aetiology for hypothyroidism following interferon therapy for breast cancer. Eur J Cancer Clin Oncol 1988;24:1299-303

30 Ronnblom LE, Alm GV, Oberg KE. Autoimmunity after alphainterferon therapy for malignant carcinoid tumors. Ann Intern Med 1991;115:178-83

31 Silvestri F, Virgolini L, Mazzolini A, et al. Development of autoimmune thyroid diseases during long-term treatment of hematological malignancies with alpha-interferons. Haematologica 1994;79:367-70

32 Vallisa D, Cavanna L, Berte R, Merli F, Ghisoni F, Buscarini L. Autoimmune thyroid dysfunctions in hematologic malignancies treated with alpha-interferon. Acta Haematol 1995;93:31-5

33 Corssmit EP, Heyligenberg R, Endert E, Sauerwein HP, Romijn JA. Acute effects of interferon-alpha administration on thyroid hormone metabolism in healthy men. J Clin Endocrinol Metab 1995;80:3140-4

34 Guerin V, Todd I, Hammond LJ, Bottazzo GF, Pujol-Borrell R, Feldmann M. Suppression of HLA class II expression on thyrocytes by interferon-alpha 1. Clin Exp Immunol 1990;79:341-5

35 Bottazzo GF, Pujol-Borrell R, Hanafusa T, Feldmann M. Role of aberrant HLA-DR expression and antigen presentation in induction of endocrine autoimmunity. Lancet 1983;ii:1115-19

36 Yue SJ, Enomoto T, Matsumoto Y, Kawai K, Volpe R. Thyrocyte class I and class II upregulation is a secondary phenomenon and does not contribute to the pathogenesis of autoimmune thyroid disease. Thyroid 1998;8:755-63

37 Kawai K, Enomoto T, Fornasier V, Resetkova E, Volpe R. Differential effects of human interferon alpha and interferon gamma on xenografted human thyroid tissue in severe combined immunodeficient mice and nude mice. Proc Assoc Am Physicians 1997;109:126-35

38 Watson PF, Pickerill AP, Davies R, Weetman AP. Analysis of cytokine gene expression in Graves' disease and multinodular goiter. J Clin Endocrinol Metab 1994;79:355-60

39 Grubeck-Loebenstein B, Buchan G, Chantry D, et al. Analysis of intrathyroidal cytokine production in thyroid autoimmune disease: thyroid follicular cells produce interleukin-1 alpha and interleukin-6. Clin Exp Immunol 1989;77:324-30

40 Durelli L, Ferrero B, Oggero A, et al. Liver and thyroid function and autoimmunity during interferon-beta $1 \mathrm{~b}$ treatment for MS. Neurology 2001;57:1363-70

41 Fabris P, Betterle C, Floreani A, et al. Development of type 1 diabetes mellitus during interferon alpha therapy for chronic HCV hepatitis. Lancet 1992;340:548

42 Fabris P, Betterle C, Greggio NA, et al. Insulin-dependent diabetes mellitus during alpha-interferon therapy for chronic viral hepatitis. $J$ Hepatol 1998;28:514-17 
43 Betterle C, Fabris P, Zanchetta R, et al. Autoimmunity against pancreatic islets and other tissues before and after interferon-alpha therapy in patients with hepatitis $\mathrm{C}$ virus chronic infection. Diabetes Care 2000;23:1177-81

44 Wesche B, Jaeckel E, Trautwein C, et al. Induction of autoantibodies to the adrenal cortex and pancreatic islet cells by interferon alpha therapy for chronic hepatitis C. Gut 2001;48:378-83

45 Oshimoto K, Shimizu H, Sato N, Mori M. A case of Addison's disease which became worse during interferon therapy: [insulin secretion under hyposmolarity]. Nippon Naibunpi Gakkai Zasshi 1994;70:511-16
46 Knost JA, Sherwin S, Abrams P, Oldham RK. Increased steroid dependence after recombinant leucocyte interferon therapy. Lancet 1981;ii: $1287-8$

47 Gisslinger H, Svoboda T, Clodi M, et al. Interferon-alpha stimulates the hypothalamic-pituitary-adrenal axis in vivo and in vitro. Neuroendocrinology 1993;57:489-95

48 Sakane N, Yoshida T, Yoshioka K, Umekawa T, Kondo M, Shimatsu A. Reversible hypopituitarism after interferon alfa therapy. Lancet 1995;345:1305

49 Wilson LE, Widman D, Dikman SH, Gorevic PD. Autoimmune disease complicating antiviral therapy for hepatitis $\mathrm{C}$ virus infection. Semin Arthritis Rheum 2002;32:163-73 